\title{
Colaboração docente e reforma dos programas escolares no Quebec
}

Teacher collaboration and the school program reforms in Quebec

Cecília Borges ${ }^{1}$

\begin{abstract}
Resumo
O presente artigo aborda o tema da colaboração docente no âmbito das reformas e políticas educativas atuais. Ele se apóia em resultados de uma pesquisa sobre as práticas colaborativas de um grupo de docentes no contexto de implantação do programa do ensino secundário quebequense. Ele busca pôr em evidência as práticas, as motivações e os fatores que contribuem para a colaboração entre os docentes, assim como os desafios por eles encontrados no seu cotidiano de trabalho. Ele sugere que, mesmo sendo vista favoravelmente, a colaboração não se integra facilmente às práticas docentes, ainda mais no contexto atual em que se impõe uma maior regulação do trabalho no seio da organização escolar. Finalmente, à luz de seus resultados, ele aponta algumas tensões e questionamentos que parecem constituir promissoras pistas de reflexão sobre o assunto.
\end{abstract}

Palavras-chave: Colaboração Docente; Trabalho Coletivo; Práticas Colaborativas; Ensino Secundário; Programa Escolar

\section{Abstract}

This paper discusses collaboration within the context of current educational reforms and policies. It is based on data collected from a research relating to the collaborative practices at a group of teachers, within the framework of the implementation of a new curriculum in secondary education in Québec. It aims to highlight the practices, the motivations, and factors that contribute to collaboration, as well as the challenges teachers met in their daily work. It suggests that, even if the teachers seem to be in favour of collaboration, it does not integrate easily into their practises, in the current context of a greater regulation of the work. Finally, this paper indicates some tensions and questions that constitute promising ways of reflexion on collaboration work.

Keywords: Teaching Collaboration; Collective Work; Collaborative Practises; Teaching Work; Secondary Education; Curricular Programs

1 Professora da Universidade de Montreal e pesquisadora associada ao CRIFPE - Centro de pesquisa Universitário sobre a Formação e Profissão Docente (Canadá). cecilia.borges@umontreal.ca. A pesquisa que apresentamos neste artigo foi desenvolvida durante um estágio pós-doutoral realizado no CRIFPE e teve o apoio do Centre de Recherche de Sciences Humaines du Canada (CRSH). 


\section{INTRODUÇÃO}

Nas últimas décadas, vários países implementaram políticas educativas visando profissionalizar a docência (TARDIF; LESSARD; GAUTHIER, 1998) e introduzir no ensino melhorias capazes de aumentar os índices de escolarização da população. No âmbito dessas políticas, a colaboração entre os diferentes atores escolares, e principalmente entre os docentes, é um dos aspectos centrais na base das transformações que afetam tanto os programas curriculares quanto a organização escolar. $\mathrm{Na}$ prática, no entanto, estudos têm evidenciado que a escola parece ser um espaço pouco propício a colaboração (BARRÈRE, 2002a; LITTLE, 1984, 1990, 2003; LORTIE, 1975; OSBORN; McNESS; BROADFOOT, 2002; TARDIF; LESSARD, 1999, dentre outros). Raros são os docentes que colaboram sistematicamente entre si e as práticas colaborativas existentes são geralmente pontuais e se inscrevem em projetos de curta duração, quando não são esvaziadas pelas crescentes exigências do trabalho escolar.

O texto que segue se interessa pela problemática da colaboração entre docentes, no contexto de implantação da reforma escolar quebequense do ensino secundário. Como os docentes do ensino secundário vivem a colaboração no seu trabalho? Quais fatores contribuem para o desenvolvimento de práticas colaborativas no âmbito da organização escolar? Qual o sentido da colaboração docente no contexto atual? Estas são algumas das questões que estaremos abordando ao longo de nossa reflexão, e isso a partir de dois enfoques, o da análise do trabalho, de um lado, e o dos estudos sobre a colaboração, de outro.

Num primeiro momento, apresentaremos o contexto reformista, tratando de situar as novas exigências, no que diz respeito à colaboração, no contexto das reformas escolares quebequenses e daquelas implementadas em diferentes países. Num segundo momento, trataremos de estudos que se interessam pelas práticas colaborativas dos docentes, evidenciando tanto os fatores que contribuem à colaboração como as tensões que estão na base dessa forma de trabalho coletivo. ${ }^{2}$ Num terceiro

2 Apoiando-nos em Lessard (2005), "colaboração no trabalho" e "trabalho colaborativo" são dois termos usados aqui indistintamente cobrindo a idéia de "trabalho em comum", compreendendo as práticas interativas entre dois ou mais profissionais do ensino que possuem um mesmo estatuto e que atuam sobre diferentes objetos: alunos, material didático, estratégias e conteúdos de ensino, projeto de estabelecimento, relação com os pais de alunos, com dirigentes escolares etc. 
momento, apresentaremos e discutiremos os resultados de um estudo recente sobre as práticas colaborativas, realizado junto a docentes de duas escolas secundárias de Montreal. À guisa de conclusão, identificaremos algumas das tensões subjacentes à exigência de práticas colaborativas entre os docentes e daremos pistas de reflexão oriundas das experiências dos docentes entrevistados.

\section{A colaboração Na base das \\ REFORMAS DOS PROGRAMAS ESCOLARES}

A exigência de uma maior colaboração entre os docentes é uma prioridade em contextos como o de Quebec, onde os novos programas curriculares se apóiam notadamente na aprendizagem e no desenvolvimento integral dos alunos, através da aquisição de competências transversais e disciplinares; na seriação escolar estruturada em ciclos de aprendizagem, ao invés da tradicional divisão em faixas etárias; na interdisciplinaridade entre as diferentes matérias de ensino; e numa maior responsabilização dos docentes pelo ensino e por seu próprio desenvolvimento profissional (Ministère de l'éducation du Québec, 2001 e 2003). Além disso, a colaboração é igualmente uma exigência incontornável na base do trabalho docente, na medida em que, com as atuais reformas quebequenses, a organização escolar, por um lado, se vê com maior autonomia e responsabilidade social, com um poder decisório local ampliado através dos Conselhos Escolares, ${ }^{3}$ e com o necessário desenvolvimento de um projeto pedagógico para cada estabelecimento de ensino (Conseil Supérieur de l'Éducation, 2003) e, por outro lado, se vê também confrontada às novas formas de regulação do trabalho,

3 Os conselhos escolares (Conseil d'établissement) são enquadrados pelas novas disposições da Lei de Instrução Pública de Quebec (Ministère de l'éducation du Québec, 2003; Conseil Supérieur de l'Éducation, 2003) e têm um caráter normativo, de gestão, articulando o projeto educativo dos estabelecimentos de ensino ao da Comissão Escolar (unidade que reúne um conjunto de escolas de uma mesma região administrativa). Ele é composto por pais de alunos que freqüentam a escola, membros do pessoal docente e não-docente e, eventualmente, membros do pessoal técnico administrativo. Desde 1997, segundo a Lei de Instrução Pública (Ministère de l'éducation du loisir et du sport, 2004), os Conselhos Escolares devem prestar contas (réddition de comptes) aos pais e à comunidade a respeito dos efetivos escolares, da idade dos alunos, da diplomação, dos resultados das provas únicas realizadas pelo Ministério da Educação, dos índices socioeconômicos da população escolar etc. 
decorrentes da obrigação de melhorar os resultados escolares ${ }^{4}$ (medidos pelos exames nacionais), da pressão parental, da concorrência entre os setores públicos, privados e entre diferentes estabelecimentos de ensino. ${ }^{5}$

Os docentes são então chamados a trabalhar de forma colaborativa no seio da equipe-ciclo e da equipe-escola; a estabelecer vínculos estreitos com a comunidade; a integrar as diferentes matérias de ensino em um conjunto harmonioso de conhecimentos que visam o desenvolvimento de competências transversais e disciplinares avaliadas ao longo de cada ciclo de aprendizagem; a agir de forma a promover a integração e o sucesso escolar de grupos de alunos cada vez mais heterogêneos (crianças e jovens portadoras de necessidades especiais, com dificuldade de adaptação e de aprendizagem, provenientes de diferentes culturas e etnias, oriundas de classes desfavorecidas etc.), e ainda, a assumirem a responsabilidade de seu próprio desenvolvimento profissional. Diante desse quadro, o apelo à colaboração requer não somente uma maior implicação docente, mas a instauração de uma nova cultura profissional que seja menos individualista e marcada pelo isolacionismo e pela especialização. Requer ainda uma cultura que faça apelo a um maior coleguismo, a uma maior cooperação e entendimento entre os docentes a fim de concretizar o projeto social de promoção da escolarização das crianças e jovens.

A emergência da colaboração nas reformas quebequenses não é, contudo, uma solitude. Ela faz eco às políticas educativas implementadas em outras províncias canadenses e também em outros países. Na província de Ontário, no Canadá anglófono, desde 1999 o Ontario College Teachers (1999) prescreve não só a colaboração docente, mas igualmente a colaboração entre os demais atores escolares (diretores, pais, membros da comunidade etc.) visando aumentar os índices de sucesso escolar e contribuir para a profissionalização no ensino.

4 A obrigação de aumentar os resultados escolares deve ser aqui compreendida no âmbito de uma política mais ampla de regulação e obrigação de resultados, fazendo referência às aprendizagens dos alunos; à responsabilidade coletiva no trabalho; à responsabilidade em relação aos meios, procedimentos ou processos de trabalho e à competência do docente, sua experiência, seu percurso durante sua formação (LESSARD; MEIRIEU, 2004).

5 A cada ano, um Palmarès das escolas secundárias é publicado na Revista Actualité. Ele é resultado de um estudo desenvolvido pelo Instituto Econômico de Montreal (IEM) e pelo Instituto Fraser que classifica por ranking as melhores escolas secundárias de Quebec, tanto anglófonas quanto francófonas. São contabilizados na análise dos dados a renda familiar, o número de alunos, o número de alunos com retardo escolar, o número de alunos com dificuldade de adaptação e de aprendizagem e portadores de deficiências e a performance escolar dos alunos nas matérias de língua materna, segunda língua, história, matemática e ciências físicas. 
$\mathrm{O}$ Australian College of Education, na Austrália, também encoraja os docentes a trabalharem juntos, tanto quanto o General Teaching Council for England (2002), na Inglaterra, que defende, no seio de suas reformas escolares, o desenvolvimento profissional docente, a abertura e o questionamento no âmbito das práticas colaborativas (LEONARD; LEONARD, 2003). Nos Estados Unidos, há mais de vinte anos, o governo vem pressionando a comunidade escolar para aumentar a eficácia do ensino e melhorar os níveis de escolarização da população. A situação é, no entanto, contraditória, pois se as exigências aumentam por um lado, isto é, se a sociedade e o governo querem poder contar com docentes mais eficazes, mais qualificados e capazes de trabalhar de forma colaborativa, constituindo uma verdadeira "comunidade de aprendizagem" (National Board for Professional Teaching, 2001; National Staff Developpement Council, 2001), por outro lado, a penúria de docentes, os salários e as condições de trabalho que se degradam, têm contribuído para se recrutar uma massa de docentes formados em programas apressados, sem formação para a docência (DARLING-HAMMOND; CHUNG; FRELOW, 2002).

Finalmente, do lado europeu, vários outros estados vêm orientando suas políticas educativas nessa mesma direção. A título de exemplo, as reformas educativas recentes na Bélgica francófona (DUPRIEZ, 2006), na Suíça (PÉRISSET-BAGNOUD, 2006) e na França (BARRÈRE, 2002b) também têm apontado para a necessidade de um aumento da colaboração e de uma formalização das práticas colaborativas entre os docentes. Porém, o que se tem evidenciado é que a colaboração não é unanimidade entre os docentes que estão no terreno de trabalho.

\section{Estudos SOBRE A COLABORAÇÃo NO tRABALHO}

Vários são os escritos com base nas teorias organizacionais a sustentar que os docentes obtêm uma melhor performance colaborando entre si (LEONARD; LEONARD, 2003). Segundo esse tipo de orientação, não só os docentes obtém uma melhor performance no trabalho, mas também seus alunos, cujos resultados escolares aumentam significativamente, contribuindo assim para o sucesso escolar. Desse ponto de vista, a colaboração é vista não só como um meio de assegurar uma maior produtividade e rendimento no ensino mas, também, como a base sobre a qual se deve construir uma nova expertise e profissionalização docente pautadas na eficácia e na performance. Vista de um outro ângulo, no entanto, a colaboração poderia ser encarada como uma forma de 
solidariedade entre os docentes, empenhados na melhoria da qualidade do ensino e no desenvolvimento da profissão. Uma "colaboração autêntica", nos dizeres de Hargreaves (apud OSBORN; McNESS; BROADFOOT, 2002). Apesar de seus benefícios incontestáveis, contudo, a colaboração não constitui efetivamente a base sobre a qual se apóia o trabalho docente, e quando os professores colaboram entre si, aos olhos destes, no entanto, a colaboração não é freqüente e está aquém de suas expectativas.

Particularmente em relação ao nosso campo de interesse, é importante reter da literatura estudada que, no caso dos docentes do ensino secundário, colaborar vem a ser ainda mais difícil do que no nível de ensino primário, visto que, no secundário, a tradição disciplinar pesa grandemente na organização curricular, na divisão por matérias de ensino, na divisão dos espaços e tempos de trabalho etc. Insuficiente, a tradição disciplinar contribui para forjar uma identidade limitada para os docentes do ensino secundário, os quais geralmente trabalham de forma isolada, funcionando em pequenas ilhas onde predominam hierarquias disciplinares e grupos fechados, ou departamentos voltados para si próprios (BORGES, 2004; BARRÈRE, 2002a; TARDIF; LESSARD, 1999; LESSARD; TARDIF, 2003; BORGES; LESSARD, 2005).

A organização departamental, aliás, exerce uma grande influência na cultura isolacionista dos docentes do secundário. Nos Estados Unidos, estudos sobre a vida departamental sugerem que, se o ensino é modelado pelo conteúdo da matéria ensinada pelo docente, isto também é valido para a cultura ou subcultura departamental que se constitui nos departamentos disciplinares das escolas secundárias (SISKIN, 1995; STODOLSKY; GROSSMAN, 1995, GROSSMAN; STODOLSKY, 1995). Isso porque a cultura departamental influencia a organização curricular, a repartição das tarefas, a repartição de poder, o clima, o ambiente de trabalho, o recrutamento, o desenvolvimento e os investimentos na carreira dos docentes, influenciando também as formas de colaboração entre eles. Nos casos em que colaboram entre si, a colaboração se dá principalmente entre aqueles docentes que ensinam uma mesma matéria e que pertencem, portanto, ao mesmo departamento. E os motivos que os levam a colaborar são: enriquecer seus conteúdos de ensino, partilhar recursos pedagógicos e didáticos operacionais, economizar tempo, assegurar a seqüência do programa e fortalecer o estatuto da sua área de conhecimento em relação às demais matérias do programa escolar. 


\section{Motivação para colaborar}

Apesar da escola não parecer um espaço propício à colaboração, as razões para colaborar existem e são diversas. Na Inglaterra, Osborne, McNess e Broadfoot (2002) constataram que durante a implantação da reforma escolar britânica muitos docentes buscaram a colaboração como uma estratégia de sobrevivência às exigências do novo programa. Com base em um modelo de análise de Little (1990), que vai da "independência" às relações de "interdependência", eles identificaram diferentes formas de colaboração, que vão das trocas sobres casos e histórias de eventos ocorridos em sala de aula ao trabalho conjunto em sala de aula (teamteaching ou conjoint work).

Nessa mesma perspectiva, Van Wessum (1999), no quadro da reforma do programa holandês identificou que a colaboração intensificouse no período de implantação da reforma, quando os docentes trabalharam de forma colaborativa na organização e produção de material didático necessário ao ensino. Ele verificou também que um consenso maior sobre a matéria de ensino acarreta formas de colaboração menos intensas, enquanto que pouco consenso ocasiona formas de colaboração mais fortes supostamente porque os professores sentem a necessidade de se harmonizar com mais freqüência e de colaborar mutuamente na preparação do material de ensino. Outros motivos para colaborar são repertoriados nos estudos e aparecem sobretudo em programas visando o desenvolvimento profissional e que buscam um maior arranjo e articulação entre o corpo professoral (LANDT, 2002; LITTLE, 1984; TARDIF; LESSARD, 1999). Também aparecem durante a etapa de inserção profissional, entre docentes noviços e experientes, quando geralmente se estabelece uma forma de tutorado, de ajuda, de apoio e de transmissão de truques da profissão do mais experiente ao novato (TARDIF; LESSARD, 1999).

A instauração de práticas colaborativas, de coleguismo, de cooperação etc., decorrentes de programas de desenvolvimento profissional, no entanto, não se faz gratuitamente, visto que depende de certos fatores que favoreçam a sua integração. Uma comparação, nos Estados Unidos, entre dois programas de formação em serviço com características comuns (LITTLE, 1984), ilustra bem a idéia de que um certo número de fatores é necessário para mudar o comportamento dos docentes. As diferenças nas formas de integração dessa experiência de formação ajudam a explicar esse fenômeno. Mencionamos aqui algumas delas. No primeiro grupo, no qual a experiência de formação teve um 
impacto positivo, os professores e os diretores foram convidados a participar do treinamento e da implantação do programa como um grupo, agentes escolares, formadores e idealizadores do programa - um acordo de trabalho também foi estabelecido com o distrito para testar idéias inovadoras. O programa foi de longa duração, com planificações semanais e experimentações em sala de aula, e os formadores e o grupo professoral, inclusive diretores, trabalharam e descobriram juntos como implementar novas idéias. Além disso, os diretores tiveram uma implicação importante no programa e exerceram uma liderança ativa na sua implantação. Já no segundo grupo, no qual a experiência de formação teve um impacto menos significativo, o convite envolvia apenas a participação do grupo dos agentes escolares no treinamento, enquanto o programa se consistia de alguns dias intensivos de treinamento em ciclos. Os participantes forneciam ainda sugestões aos formadores, que recolhiam de forma receptiva as sugestões e ajustavam a formação. Os diretores, no entanto, participaram apenas pontualmente de algumas atividades.

Visivelmente, a forma de organização e de desenvolvimento dos programas parece ter tido um impacto significativo nas práticas docentes a posteriori. Isso confirmaria a hipótese de que, para instaurar uma cultura de colaboração entre os agentes escolares, faz-se necessário a presença de um ou mais dos fatores que se seguem e que aparecem nas recomendações de diversos estudos (LEONARD; LEONARD, 2003, LITTLE, 1984, 1999, 2003; INGER, 1993; BARRÈRE, 2002b; VAN WESSUN, 1999 etc.). Quais sejam um engajamento e responsabilizações coletivas; uma proposta de formação calcada numa articulação profunda entre teoria e prática, no trabalho minucioso de discussão coletiva, de planificação, de experimentação em sala de aula e de posterior avaliação coletiva, o que implicaria uma maior latitude em relação ao programa; uma duração significativamente longa, visto que novas práticas precisam de tempo para serem testadas e validadas pelo coletivo de professores; uma preocupação em garantir espaços de trabalho coletivo, de discussões, mas também de observação mútua do trabalho que se faz em sala de aula; uma organização dos tempos e espaços de trabalho propícia à colaboração, e, finalmente, uma significação do ato de colaborar, isto é, seria desejável que os agentes escolares encontrassem um sentido em colaborar no trabalho.

\section{Os DESAFIOS DA COLABORAÇÃo}

As motivações para colaborar, vimos nos estudos acima, são diversas e dependem de uma série de fatores que contribuem para o seu 
desenvolvimento. Mas também existem desafios decorrentes de práticas colaborativas e, dependendo da sua importância, eles podem influenciar o sucesso ou não destas. Um deles é o de criar uma cultura de colaboração entre os docentes, exigindo destes uma formalização das práticas colaborativas através da constituição de equipes-ciclos ou equipes-escolas e de um maior acordo e coerência entre os agentes escolares, ao mesmo tempo que se atribui uma maior autonomia aos estabelecimentos de ensino, numa perspectiva de regulação local do trabalho (BARRÈRE, 2002b). Nesse sentido, a colaboração deve ser formalizada, documentada e integrada ao projeto pedagógico da escola, demandando dos docentes mais visibilidade, partilha e regulação de atividades e práticas que, anteriormente, se faziam individualmente no espaço privado da sala de aula, tais como a definição das metas educativas, o planejamento anual ou diário, a seleção do conteúdo e do material de apoio, o modo de apresentação do conteúdo, os métodos e técnicas utilizados no ensino, as formas de avaliação dos alunos etc.

Tudo isso, evidentemente, produz um sentimento de insegurança e de instabilidade nos docentes, ainda mais nos do secundários, que tendem a se apoiar fortemente no espaço fechado e seguro dos seus conteúdos disciplinares. Além disso, é importante notar que as práticas colaborativas nesse contexto correspondem a uma demanda externa e não dizem respeito às reais preocupações dos docentes referente aos problemas do fracasso escolar, dos alunos com dificuldades de adaptação escolar ou de aprendizagem, da falta de ferramentas de trabalho e de material didático atualizados e atraentes, da falta de tempo, das condições de trabalho muitas vezes inadequadas, dos salários não satisfatórios etc. Para agravar a situação, um outro desafio a superar decorre do fato de que, na maioria das vezes, os vínculos estabelecidos nas relações de trabalho entre os diferentes agentes escolares são frágeis, marcados ou pela instabilidade de início de carreira, ou por competições entre áreas de conhecimento e seus departamentos respectivos, por disputas de poder ou, ainda, por uma tendência à discrição e à cautela em face do grupo onde cada um tenta construir, afirmar ou preservar a sua reputação. Muitos docentes aliás se sentem ameaçados pelas atividades colaborativas, já que estas podem deixar transparecer sua vulnerabilidade. Isto é, o fato de desvelar sua prática ao colegas, de partilhar suas dúvidas e crenças expõe o docente, com suas forças e fraquezas, arriscando a sua reputação, ou pior ainda, construindo, às vezes, uma reputação negativa de si mesmo frente aos colegas. É bem isso que pôs em evidência Barrère (2002b), em seu estudo sobre as práticas colaborativas dos docentes dos liceus e dos colégios na França, onde o medo de arriscar a sua reputação ou de "perder a cara" engendrou um 
distanciamento dos docentes em relação às práticas colaborativas. $\mathrm{O}$ mesmo pôde observar Rosenholtz (1991) no Estados Unidos, em seu estudo sobre a organização escolar, no qual certos docentes confessaram sua apreensão quanto à pedir ajuda a um colega, simplesmente, por medo de perder a face, de expor-se diante de seus colegas, deixando transparecer suas dúvidas e incertezas.

Um último desafio a mencionar, diz respeito ao fato de que, ainda que os diferentes fatores que contribuem para a colaboração sejam bem conhecidos, estes parecem não fazer eco nos ouvidos dos políticos e idealizadores das reformas. Enfim, tudo isso e, particularmente, a dificuldade dos docentes em integrar a cultura da colaboração nos conduz a questionamentos sobre a maneira como os docentes vivem a colaboração no seu trabalho. O que acontece quando ela é institucionalizada e se torna uma norma? Quais razões eles encontram para colaborar? Qual é o seu papel nas injunções colaborativas atuais?

Vejamos como os docentes de duas escolas secundárias de Quebec vivem-na em seu trabalho.

\section{A colaboração durante a fase de EXPERIMENTAÇÃo DO PROGRAMA ESCOLAR}

Nós apresentamos alguns dos fatores que contribuem para a emergência da colaboração no trabalho, tais como a reorganização dos tempos e dos espaços de trabalho e a atribuição de uma maior latitude e autonomia no trabalho de apropriação do programa pelos agentes escolares. De certa maneira, é bem isso o que tentou fazer o governo de Quebec no contexto de implantação da reforma escolar junto à quinze escolas-piloto, escolhidas a partir de uma base voluntária para experimentar o novo programa. Essas escolas se beneficiaram não só de autonomia mas, também, de recursos financeiros para reorganizar os tempos e espaços de trabalho, assim como de atividades de formação específicas para implantação do novo programa. Em contrapartida, os docentes, particularmente os do primeiro ciclo do secundário, tinham que conceber e pôr em prática situações de aprendizagem com base no desenvolvimento de competências disciplinares e transversais, e isso tanto no âmbito de suas matérias de ensino quanto em relação às outras matérias, em projetos interdisciplinares. Eles tinham igualmente que documentar as situações de aprendizagem propostas e deixar traços do processo de concepção, de aplicação e de avaliação destas. E tudo isso com a obrigação de trabalhar de forma colaborativa. 
Em nossa pesquisa, estudamos o modo como um grupo de professores de duas das quinze escolas-piloto viveram o processo de apropriação do programa no seu segundo ano de implantação. ${ }^{6}$ Nós realizamos dez entrevistas com professores de diferentes matérias, história, ciências, francês, educação física, moral, matemática e ciências. As entrevistas, semi-estruturadas, abordavam diferentes aspectos do novo programa, com questões sobre as práticas colaborativas entre os docentes do primeiro ciclo do secundário, durante o processo de apropriação e implantação do novo programa, por exemplo. Além das entrevistas, acompanhamos quinze encontros de formação visando a apropriação do programa.

As escolas, uma pública (Escola $A)^{7}$ e outra privada confessional (Escola B) ${ }^{8}$ possuíam características bem distintas em termos de organização do trabalho, do pessoal, da liderança da direção e particularmente em relação à forma de integrar o programa. Não trataremos aqui dessas características que certamente não podem ser negligenciadas

60 primeiro ano de implantação (2002-2003), correspondeu à leitura e estudo do programa escolar. Lembramos que o ano escolar em Quebec se reparte em dois anos, começando em setembro e terminando em junho, mais precisamente no dia 23. Os docentes fizeram então suas recomendações que foram acolhidas e integradas pelo comitê gestor da reforma. O segundo ano (2003-2004) foi o ano da elaboração de situações de aprendizagem e de experimentação em sala de aula. No terceiro ano (2004-2005), o novo programa foi estendido à sessenta e duas escolas da província que foram designadas para experimentar o programa; estas não receberam o mesmo financiamento para formação e apropriação que as escolaspiloto. No quarto ano (2005), a reforma foi ampliada para toda a rede de ensino.

7 A Escola A, pública, acolhe um grande número de alunos de escolas primárias da região onde ela se localiza e é freqüentada por famílias de classe média e de meio desfavorecido. Vária etnias estão representadas na escola que possui em torno de 1.803 alunos. Como muitos dos estabelecimentos que buscam atrair uma clientela cada vez maior e de melhor nível, devido ao concorrido mercado das escolas secundárias, a Escola A oferece um programa alternativo de caráter interdisciplinar (programme enrichi) para alunos que possuem um rendimento e uma capacidade de auto-organização e de auto-responsabilização superior à média; estes são geralmente escolhidos através de um exame de seleção. Ela oferece também classes fechadas para alunos imigrantes recém chegados em Quebec (classes d'accueil), um grande setor de adaptação escolar para alunos com dificuldade de aprendizagem e de adaptação, além de turmas regulares e uma classe de apoio que oferece um reforço nas áreas de matemática e francês aos alunos com dificuldades nestas matérias. Quanto aos profissionais efetivos, a escola contava com 185 membros, combinando pessoal docente e não-docente. Implicados na apropriação do programa, estavam 24 docentes dos dois primeiros anos do primeiro ciclo do secundário, o diretor das classes d'accueil, a diretora do primeiro e segundo ano do secundário, dois psicopedagogos e os conselheiros pedagógicos da Comissão Escolar. A diretora da escola participou esporadicamente de alguns encontros de formação, e geralmente ela era responsável pela acolhida dos participantes.

8 A Escola B, privada confessional, oferece dois programas um francófono e outro anglófono, paralelos e independentes, com um corpo de docentes distinto e com uma vice-direção para cada programa. Nosso estudo foi realizado no programa francófono. Trata-se de uma 
mas destacamos apenas alguns aspectos singulares dos encontros de formação em cada uma das escolas estudadas, já que isso repercute na forma como os docentes se apropriaram do programa, ao longo dos anos 2003-2004.

$\mathrm{Na}$ Escola A os encontros de formação se realizaram na presença do diretor e vice-diretores, conselheiros pedagógicos da Comissão Escolar à qual a escola é vinculada, e na presença dos especialistas do ensino, enfim, do pessoal não-docente; todos engajados com os professores na apropriação do programa. Enquanto na Escola B, os encontros se realizavam na presença de uma conselheira pedagógica do próprio estabelecimento e da vice-diretora, que se fazia presente esporadicamente.

Nas duas escolas os encontros de formação eram animados por conselheiros pedagógicos. Na Escola A, no entanto, com um maior número de alunos e de professores implicados no processo, eles contavam com um conselheiro por matéria, enquanto na Escola B, com um menor número de alunos e de docentes, contavam somente com a ajuda da conselheira pedagógica da própria escola, que, aliás, cobria o trabalho de implantação tanto no programa francófono quanto anglófono.

Além dessas diferenças, uma outra igualmente importante, é a de que, na Escola A, os professores decidiram em assembléia participar da experimentação do novo programa. Já na Escola B, segundo informação dos próprios professores, a decisão já tinha sido tomada quando eles foram consultados, ou bem, informados de que a escola se apresentava como voluntária à experimentação. Conforme disseram, eles consentiram em participar porque, de todo modo, o novo programa terminaria por atingílos, mais cedo ou mais tarde, e ainda porque, como escola-piloto, eles se beneficiariam dos recursos alocados pelo governo para a experimentação. A consciência de que sua participação nesse processo de experimentação traria inúmeras vantagens e benefícios para a escola era partilhada pelos

para meninas somente e possui em torno de 1.000 alunas provenientes de classe média favorecida. Diferentes etnias estão igualmente representadas nesse estabelecimento. A escola, com uma orientação forte no desenvolvimento pessoal e religioso das alunas, possui um movimento pastoral de jovens, oferece muitas atividades artísticas e paraescolares. Ela oferece ainda um programa chamado Objetivo Francês que acolhe alunas das classes regulares, na maioria imigrantes com dificuldade em francês. 0 efetivo profissional implicado na reforma, do lado francófono, era formado por quinze docentes das diferentes matérias e uma conselheira pedagógica responsável pela implantação do programa. A vice-diretora para o programa francófono freqüentava ocasionalmente os encontros de formação. 
docentes dos dois estabelecimentos. Mas como veremos mais adiante, na Escola A já existiam certas predisposições e uma abertura à implantação do novo programa.

\section{A COLABORAÇÃO NA VISÃo dOS PRÓPRIOS DOCENTES}

$\mathrm{Na}$ prática, como os docentes que entrevistamos reagem à colaboração? Nossos resultados vão ao encontro do que dizem boa parte dos estudos sobre a colaboração, isto é, em geral, os docentes consideram a colaboração favoravelmente. Eles vêem, aliás, várias vantagens nisso e consideram que ela contribui particularmente para aproveitar as forças e qualidades de cada um dos membros da equipe docente; para maximizar o trabalho na nova organização escolar, à fim de responder aos objetivos do novo programa; para partilhar as tarefas e diminuir o peso do trabalho; para enriquecer e partilhar as especialidades de cada um; para apoiar as intervenções em sala de aula e para desenvolver um espírito de solidariedade entre os docentes.

Alguns de nossos depoentes indicaram ainda que a colaboração será "uma questão de sobrevivência para os docentes do ensino secundário" $(\mathrm{E} 6 \mathrm{C})^{9}$ na nova organização escolar, estruturada em ciclos e com ênfase na interdisciplinaridade, sobretudo em função do número de alunos que os docentes do secundário têm sob sua responsabilidade. Essa forma de encarar a colaboração vai ao encontro dos resultados do estudo realizado por Osborne, McNess e Broadfoot (2002), em que a colegialidade e a colaboração eram vistas como uma forma de superar as dificuldades advindas com a implantação do novo programa curricular.

Os benefícios da colaboração, embora presentes no discurso dos nossos depoentes, não gozam de unanimidade. As práticas colaborativas são intermitentes, aleatórias e, para alguns, inexistentes. Isso não quer dizer que nossos entrevistados rejeitassem a colaboração por princípio. Ao contrário, várias práticas colaborativas puderam ser observadas durante nossa permanência nas escolas, assim como diversos fatores que retardam ou dificultam a sua emergência.

9 Este código corresponde ao número do entrevistado (E) e à sua matéria de ensino: E5Ma (matemática), E6C (ciências), E7H (história), E10EF (educação física) e E9M (moral), E4Ma (matemática), E2F (francês), E3F (francês). 


\section{As PRÁTICAS COLABORATIVAS}

Nas duas escolas estudadas, nós contatamos várias praticas colaborativas, muitas delas, no entanto, já existiam muito antes da implantação do novo programa. Quanto ao tipo de práticas colaborativas, elas são de duas ordens, formais e informais. Deixando à parte os conselhos de classe, as práticas formais dizem respeito ao trabalho coletivo realizado durante encontros formais de apropriação e implantação do programa, ou durante encontros organizados pelos próprios docentes em companhia ou não dos conselheiros pedagógicos, para tratar da planificação e da elaboração das situações de aprendizagem a serem testadas em sala de aula. Por outro lado, as práticas informais se davam sobretudo no horário do almoço, nas pausas entre uma aula e outra, ou no fim do dia com o término das atividades. Elas consistiam em trocas informais sobre histórias e casos, eventos passados em sala de aula, mas também sobre questões e problemas pessoais.

Nas práticas colaborativas formais, particularmente, observou-se:

- partilha, troca de material didático, de livros-texto, de material de apoio ao ensino, de planos de curso, de exames etc.;

- trocas sobre as dificuldades encontradas no ensino para abordar um tema no contexto do novo programa, para preparar uma situação de aprendizagem, para organizar uma tarefa, uma avaliação etc.;

- trocas sobre problemas enfrentados com os alunos, sobre um aluno em particular, sobre problemas de aprendizagem ou de indisciplina em classe etc., e também sobre problemas pessoais;

- planificação conjunta durante a concepção e elaboração das situações de aprendizagem a serem testadas e documentadas segundo a demanda ministerial;

- co-ensino (três casos), isto é, professores ensinando juntos a um mesmo grupo de alunos (team-teaching ou conjoint work)

$\mathrm{Na}$ Escola A, muitos dos docentes implicados na experimentação do programa já possuíam uma certa disponibilidade para o trabalho colaborativo. No setor de adaptação escolar e na classe de apoio francêsmatemática, por exemplo, já era comum os professores colaborarem entre si na planificação e inclusive no ensino em sala de aula. Além disso, quatro 
professores implicados na implantação do novo programa estavam na origem de um programa alternativo interdisciplinar. Estes tinham, portanto, bastante experiência de planificação e ensino em colaboração, já que eles planejavam conjuntamente as atividades curriculares, desenvolviam projetos interdisciplinares, além de, ocasionalmente, ensinarem conjuntamente aos seus alunos. Esse grupo de docentes exercia então uma liderança na escola, constituíam um grupo de vanguarda, uma referência para o corpo professoral que experimentava o novo programa. Nessa escola havia ainda uma grande sinergia entre os professores que colaboravam também informalmente e com freqüência, partilhando constantemente entre si problemas do dia-a-dia na escola e também problemas pessoais, trocando material, referências e idéias, e organizando atividades sociais e saídas em grupo.

Durante o período de implantação da reforma, nas reuniões de apropriação e de formação do novo programa, era possível ver os professores atuando nas diferentes equipes de trabalho de forma engajada, participante, crítica e tomando iniciativas. Notou-se que os professores conservaram os mesmos grupos por área (educação física, artes, ciências e tecnologia, matemática e universo social, englobando história, geografia e moral) e, tanto quanto possível, eles se articulavam segundo suas afinidades pessoais. Isso não impediu que docentes novos na escola assim como os noviços se integrassem progressivamente nas equipes. Os encontros de formação eram bastante dinâmicos e geralmente se dividiam em duas partes: uma geral, coletiva, para relembrar certos pontos principais da reforma, expor a atividade a realizar, assim como para orientar os professores quanto aos principais pontos a serem trabalhados nos grupos, e outra de trabalho em atelier, com as equipes de área. Os conselheiros pedagógicos, um para cada área, serviam de guia, de tradutores do programa, de pessoas-recurso, contribuindo na concepção, elaboração, aplicação, avaliação e documentação das situações de aprendizagem produzidas pelos docentes. Um representante do Ministério da Educação, designado para acompanhar a escola durante a implantação da reforma, participou de ao menos três encontros de formação para reforçar o trabalho da equipe dos docentes do primeiro ciclo do secundário. A pedido dos próprios professores, no final do ano escolar, o representante do ministério fez um balanço das situações de aprendizagem realizadas pelos professores e que tinham sido enviadas à equipe do Comitê de Gestor da Reforma do Ministério da Educação. Esse momento foi bastante apreciado pela equipe 
que, contudo, esperava um feedback mais detalhado, indicando as falhas e pontos fortes das situações de aprendizagem.

$\mathrm{Na}$ Escola B, a disponibilidade para o trabalho em colaboração parecia mais restrita. Segundo nossos depoentes, antes da experimentação do novo programa, as trocas e intercâmbios eram esporádicos, menos intensos e restritos a dois ou mais docentes de uma mesma matéria. Assim, essa era a primeira vez em que eles se viam "obrigados" a trabalhar conjuntamente na elaboração de projetos de ensino, isto é, nas situações de aprendizagem. Nos encontros de formação, eles pareciam sempre reticentes, insatisfeitos, rebarbativos e encontravam com freqüência impedimentos para colaborar durante a concepção, elaboração e aplicação das situações de aprendizagem. Isso não quer dizer que não houve colaboração. Na prática, ela deu-se sobretudo entre docentes de um mesmo campo ou domínio disciplinar, isto é, com exceção dos responsáveis por inglês e artes, e por matemática e educação física, que elaboraram projetos integrados, os demais docentes produziram situações de aprendizagem nas suas respectivas matérias de ensino. A particularidade desse grupo de professores é que eles se queixavam do pouco tempo que tinham para trocas e para o trabalho em comum; breve, a colaboração parecia realmente insatisfatória aos olhos deles.

Quanto aos encontros de formação, estes eram animados pela única conselheira pedagógica da escola, e na maior parte do tempo estes tinham a forma de um curso magistral, isto é, a conselheira assumia a responsabilidade de apresentar e decodificar conceitos-chave da reforma e preparar ferramentas de trabalho, como foi o caso da produção de um instrumento informatizado para redigir as situações de aprendizagem, por exemplo. Frente a esse tipo de formação, os docentes não pareciam convencidos da pertinência dos encontros e reclamavam da falta de tempo para trabalharem juntos e intercambiar idéias e críticas em relação ao programa. Nas raras ocasiões em que os professores deveriam trabalhar em equipe no quadro de um ou outro atelier proposto pela conselheira pedagógica, contraditoriamente, eles reclamavam o tempo todo e realizavam a contragosto a atividade proposta. $\mathrm{O}$ único momento em que o encontro de formação e apropriação do programa pareceu-lhes verdadeiramente interessante foi o final do ano escolar, quando eles apresentaram ao conjunto de seus colegas as situações de aprendizagem realizadas. Então, surpresa e decepção emergiram entre os docentes. Surpresa em relação à qualidade e originalidade dos trabalhos. Decepção 
em relação às dificuldades vivenciadas durante o processo de experimentação das situações de aprendizagem junto aos alunos, mas sobretudo em relação ao fato de eles terem percebido que vários ajustamentos poderiam ter sido feitos para melhorar as situações de aprendizagem se eles tivessem se comunicado mais seguidamente entre si. Uma professora de francês, particularmente decepcionada pela falta de comunicação entre os docentes, explicou que, por razões diferentes, tanto ela como os professores de geografia haviam trabalhado sobre a descrição da cidade de Montreal sem, em nenhum momento, terem estabelecido um vínculo entre os seus trabalhos. "Nem os alunos fizeram a transferência dos conhecimentos de uma matéria para outra" (E3F), prova de que realmente nenhuma conexão foi estabelecida.

Em resumo, havia uma grande diferença entre os estabelecimentos estudados quanto à forma de integrar a colaboração nas suas práticas educativas. Na Escola A, mais que na B, sentimos um clima mais favorável ao desenvolvimento de práticas colaborativas. Esse clima era sustentado pelos arranjos em termos de horários e locais de trabalho, o que facilitava as trocas e os encontros entre os docentes. $\mathrm{Na}$ Escola A, por exemplo, a tradicional divisão departamental tinha sido abolida, e os docentes do primeiro ciclo do primário, com exceção dos de educação física, partilhavam um único e grande local de trabalho. Esse tipo de arranjo na Escola B era praticamente impossível, devido aos espaços de trabalho restritos e pequenos.

De todo modo, nas duas escolas, as prática colaborativas se realizaram, mas elas pareciam longe de satisfazer as expectativas dos docentes que dificilmente viam a sua integração no cotidiano. Eles consideravam que colaborar no quadro de ações mais formalizadas e durante todo um ano letivo era quase que impossível para um professor do secundário, a não ser que a colaboração fosse pontual e esporádica.

Eles reconheciam igualmente que o engajamento e motivação de seus alunos tinham aumentado depois que eles começaram a trabalhar conjuntamente nas diferentes situações de aprendizagem, mas eles não se sentiam tão seguros em relação à aprendizagem dos alunos. Afinal, desde que o novo programa começara a ser implantado, o que estes apreenderam efetivamente em termos de conhecimentos e competências?

Enfim, nossa percepção dos dois contextos observados é de que a experiência vivida pelos docentes não parecia suscitar um sentimento de "colaboração autêntica", nos dizeres de Hargreaves, citado por Osborne, 
McNess e Broadfoot (2002). Mais especificamente, o que queremos dizer é que as trocas, os intercâmbios, os acordos, a tomada de decisão coletiva etc., que observamos, pareciam artificiais aos olhos dos docentes e não pareciam ir ao encontro de suas verdadeiras preocupações e aspirações. A colaboração parecia se realizar na forma do ensaio e do erro; ela não suscitava o engajamento do conjunto de docentes e era restrita aos grupos de docentes que já tinham uma disponibilidade para o trabalho colaborativo, decorrente do fato de que estes já partilhavam uma visão comum a respeito do ensino.

\section{DificuldADES E OBSTÁCULOS À COLABORAÇÃo}

Em um artigo precedente (BORGES; LESSARD, 2006), nós identificamos três ordens de fatores que dificultam a colaboração: condições de trabalho, estrutura curricular e identidade ou cultura disciplinar dos docentes do ensino secundário.

As condições de trabalho dizem respeito mais particularmente à falta de tempo, à sobrecarga resultante dos horários de trabalho intensos, ao número de alunos por classe e ao número de alunos por docente, que são, sem sombra de dúvida, pouco favoráveis à colaboração. Elas decorrem, evidentemente, da estrutura e do modo de funcionamento da escola secundária, os quais sempre constituíram uma barreira a uma maior integração entre os docentes desse nível de ensino e mesmo entre aqueles que ensinam uma mesma matéria: "os horários entrecortados e supercarregados, o número de alunos que um docente encontra em uma semana variando entre 180 e 200, as turmas cada vez mais heterogêneas, as pausas desencontradas etc.” (E6C), constituem barreiras e não encorajam os docentes ao trabalho colaborativo, à planificação e ao ensino conjunto. No contexto de implantação da reforma, os docentes reclamavam também da falta de tempo para se apropriarem do novo programa, para estudá-lo e conhecê-lo mais profundamente.

A estrutura curricular diz respeito à divisão por departamentos que contribui para o distanciamento entre professores de diferentes matérias. "Como fazer a transversalidade quando a gente não conhece nem o professor que está na sala ao lado?” (E10EF) ressaltou um professor de educação física. Apesar da implantação do novo programa, a departamentalização é um problema que está longe de ser resolvido e ela gera seguidamente muitos problemas de comunicação entre os professores 
e impede vínculos possíveis entre as matérias, como no caso que citamos acima, dos professores de francês e geografia que descobriram ao final do ano que tinham desenvolvido um mesmo tema nas suas respectivas situações de aprendizagem.

A estrutura curricular sobrecarregada também gera um sentimento de impotência, de cansaço no trabalho. Alguns dos docentes entrevistados falaram de uma fadiga, um cansaço que foi se instalando e que culminou, no final do ano escolar, em um esgotamento de forças. Eles falaram ainda de uma corrida contra o tempo, principalmente em relação a cobrir todos os conteúdos, a fim de responder às exigências do Ministério da Educação, exigência esta que se torna bem presente na vida dos docentes na forma dos exames ministeriais.

A inquietude em relação aos conteúdos a ensinar vai ao encontro das constatações de Siskin (1991), Stodolski e Grossman (1995), Grossman e Stoldoski (1995). Esse sentimento é ainda mais forte em matemática e francês visto que essas matérias determinam a seleção escolar. De fato, os docentes se sentem numa encruzilhada entre o novo programa escolar e a pressão para assegurar os índices de sucesso nos exames escolares. Assim, responder à demanda ministerial para desenvolver situações de aprendizagem em acordo com o coletivo docente e na perspectiva do novo programa e, ao mesmo tempo, cobrir todo o conteúdo para assegurar os índices de aprovação nos exames é uma equação complexa de se resolver para muitos dos nossos entrevistados. Em face disso, certos professores dizem que a reforma não é nem um pouco realista.

A cultura disciplinar, ou a cultura docente no secundário parece constituir igualmente um obstáculo à colaboração. Vários entrevistados insistiram sobre esse aspecto. Disseram que não estão habituados a trabalhar em equipe e, logo que tentam, são confrontados seguidamente com problemas de diferentes ordens, que retardam o trabalho, fazendo-os duvidar da colaboração, que parece então gerar um efeito contrário àquele de somar as forças da equipe, de partilhar o trabalho etc. Qual a razão para tal resistência? Medo de se expor, individualismo, crenças não compartilhadas em relação à forma de ensinar um mesmo conteúdo?

Alguns docentes mencionaram a resistência dos colegas de um mesmo campo disciplinar para trabalhar em colaboração. Uma jovem professora de matemática manifestou seu descontentamento em relação aos seu parceiro de área: "tantas dúvidas, tantas questões e a necessidade de partilhá-los" (E5M), mas seu colega de área, não sentindo a mesma 
necessidade que ela, não atendia aos seus apelos de colaboração. Ela passa a enfrentar uma solidão em sua própria disciplina, "justo no momento em que o novo programa propõem mudanças maiores no ensino da matemática!' (E5M), e busca então se articular com os colegas que ensinam francês, implicando-se em uma situação de aprendizagem interdisciplinar.

Nossos depoentes também citaram o individualismo. Diz uma professora de moral: "tem muitos professores que preferem estar sozinhos, fazer suas coisas... correto, mas isto é individualista!"(E9M). O individualismo vem a ser um aspecto da cultura docente ou é bem o resultado de uma organização curricular que a cultiva? (CARPENTIERROY; PHARAND, 1992 apud TARDIF ; LESSARD, 1999) Tardif e Lessard (1999) dizem que existe uma cultura individualista que domina o ensino, particularmente o secundário. Barrère (2002a) fala do isolamento disciplinar e do "luto da disciplina" do qual sofrem os docentes do secundário em face dos novos programas cada vez mais centrados no aluno e nos processos de aprendizagem.

Sobre esse aspecto, vários depoentes insistiram que se trata simplesmente das características pessoais de cada um: "depende da personalidade da pessoa" (E4Ma) diz uma professora de matemática. "Depende da abertura de espírito, para se expor e partilhar suas idéias em grupo" (E2F) exclamou uma outra de francês. A título de exemplo, segundo dois dos nossos entrevistados que participaram na criação do Programa alternativo interdisciplinar, da Escola A, o grupo passou por altos e baixos, por momentos de alegria mas de muita dificuldade, nos quais eles se disseram certas "verdades" $(\mathrm{E} 7 \mathrm{H})$, momentos de tensão em relação à forma de trabalho de cada um, às crenças de cada um etc., o que não impediu que o projeto florescesse e que eles mais tarde pudessem se regozijar por tê-lo criado, sentindo prazer por trabalhar em equipe.

\section{DiscussÃo: ALGUMAS TENSÕES}

Os obstáculos que acabamos de mencionar sem dúvida influenciam a emergência ou não das práticas colaborativas. Eles são, aliás, bem conhecidos da literatura sobre o trabalho docente e isso remonta a Lortie (1975), que ressaltou que as escolas não constituem um lugar favorável à colegialidade, nem ao desenvolvimento de relações mais estreitas entre os professores. Apesar desses obstáculos, contudo, vimos que a colaboração emergiu entre os docentes entrevistados das duas escolas. Principalmente na Escola A, onde a forma de apropriação do novo 
programa, o apoio dos conselheiros pedagógicos, o leadership da direção, a reorganização dos espaços e tempos de trabalho, além de certas predisposições, como a experiência do programa alternativo interdisciplinar, pareciam exercer uma influência notável sobre os professores. Enquanto na Escola B, apesar dos esforços notáveis da conselheira pedagógica e do empenho de nossos depoentes, a colaboração parecia realmente dar o seus primeiros passos. Partindo dos nossos resultados, porém, queremos chamar a atenção do leitor não tanto para uma comparação possível entre as escolas estudadas, mas, sobretudo, para algumas tensões que parecem estar na base das relações de colaboração docentes.

A primeira tensão diz respeito ao risco de se expor, ao medo de ser avaliado, julgado e etiquetado, e à colaboração vista como importante propulsor de relações de ajuda, de partilha etc., servindo assim de ferramenta de desenvolvimento profissional. No caso de nosso estudo, muitos docentes mencionaram a postura individualista dos professores do secundário como uma barreira à colaboração. A causa desse individualismo merecer ser explorada, visto que, mais do que significar um traço da personalidade de cada um, ela parece estar vinculada ao risco de exposição ao julgamento pelos pares (BARRÈRE, 2002b; LIT'TLE, 1984, 1990; RONSENHOLTZ, 1991).

Desse modo, expor seus pensamentos, mostrar sua forma de trabalho, abrir a porta de sua classe e revelar sua prática pedagógica tornase arriscado. Muitos professores têm medo de receber críticas, de tornar pública sua forma de agir. Se um professor não consegue resolver um problema em sua classe, ele tem medo de ser julgado como fraco, incompetente no trabalho, sem pulso ou incapaz de gerenciar sua classe. Certos professores preferem suportar suas dificuldades a partilhá-las com seus colegas; e se eles conseguem se defender e bem resolver o problema, melhor ainda, pois isso contribui para criar uma imagem de competência perante o conjunto dos professores (BARRÈRE, 2002b). A literatura sobre o trabalho docente ressalta ainda que é comum um professor noviço pedir ajuda a um outro mais experiente, mas o noviço muitas vezes se sente em uma situação delicada, ou melhor, arriscada já que, durante a fase probatória, é preciso provar sua competência e um pedido de auxílio pode ser visto com sinal de incompetência (RONSENHOLTZ, 1991).

Visto sob esse ângulo, a colaboração se afasta do seu potencial inovador que encontramos nos escritos sobre a inserção e desenvolvimento 
profissional docente (LANDT, 2002; TARDIF; LESSARD, 1999), particularmente quanto à relação entre docente expert e docente noviço. Distancia-se igualmente das formas de resistência ao trabalho, no quadro de lutas sociais nas quais os trabalhadores docentes desenvolvem laços de solidariedade para lutar por melhores condições de trabalho, de salário, de formação, de inserção na profissão e de desenvolvimento na carreira.

Uma segunda tensão diz respeito à perda de controle do seu trabalho individual e à apropriação coletiva do trabalho. Isto é, além de terem que superar as condições de trabalho, a estrutura curricular e a cultura disciplinar não favoráveis à colaboração, nossos depoentes tiveram que assimilar o fato de que, com o novo programa, as decisões sobre diferentes aspectos de suas tarefas que até então eram feitas individualmente (planificação, elaboração, avaliação das situações de aprendizagem, por exemplo), passariam a ser feitas coletivamente. Em relação a esse ponto, nós podemos nos questionar se o fato de instaurar uma cultura colaborativa não constituiria um perigo, um entrave para a autonomia docente. $\mathrm{Na}$ mais estruturante das reformas, os docentes sempre conseguiram preservar seu espaço de liberdade e autonomia; a sala de aula, aliás, sempre foi um espaço de resistência aos modismos, mas ela também foi e tem sido um espaço onde práticas alternativas e inovadoras viram a luz do dia.

Evidentemente nós podemos nos questionar se esse espaço fechado da sala de aula, a caixa preta, não está a esconder um trabalho solitário e que nem sempre é exemplar, isto é, que não segue as orientações, as regras da arte do métier, enfim, responsabilidades educativas e éticas inscritas no programa em relação às aprendizagens dos alunos e que regem a profissão. Sob esse ângulo, somos levados a crer que é preciso, sim, abrir a caixa preta e estabelecer coletivamente as bases e princípios diretores e reguladores da profissão docente. Nesse sentido, ao invés de se deixar levar por diretrizes, orientações e regras que vêm de cima para baixo, os docentes deveriam buscar definir os princípios norteadores do seu trabalho nas próprias raízes do trabalho curricular efetivo e na base da organização escolar. Isso significaria uma responsabilização e tomada de decisão coletivas, engendrando assim uma apropriação coletiva do trabalho pelos próprios docentes trabalhadores.

Uma terceira tensão vem da ambição reformista em relação às reais preocupações dos docentes. Nas reformas atuais, os docentes são chamados à colaborar para alcançar os objetivos ambiciosos do programa escolar: desenvolvimento de competências transversais e disciplinares, metacognição, desenvolvimento pessoal e social dos alunos, integração 
de alunos com dificuldades de adaptação, de aprendizagem e com limitações físicas, manutenção e aumento dos níveis de sucesso escolar etc. Ao mesmo tempo, conservam-se dispositivos tradicionais de avaliação, as mesmas formas de gestão e de financiamento da educação, que vão no sentido de uma redução dos custos e investimentos educativos. Solicitase um engajamento dos docentes sem precedentes, pede-se que eles sejam mais produtivos e que os resultados escolares melhorem etc., sem que as condições de trabalho sejam alteradas, sem que sejam oferecidos os meios e condições necessários para a implantação do novo programa e, sobretudo, sem levar em conta as reais preocupações dos docentes.

Em relação às preocupações dos docentes, Barrère (2002b) apresesenta um exemplo interessante de professores atuando em uma escola localizada em uma Zona de Educação Prioritária (ZEP). Em seu estudo, fazia mais sentido para os docentes se reunir e trabalhar conjuntamente sobre os problemas relacionados às dificuldades que eles enfrentavam para ensinar aos alunos julgados extremamente difíceis, que colaborar sobre os objetivos ambiciosos da reforma escolar francesa. Essa urgência dos professores em considerar particularmente as dificuldades do dia-a-dia escolar, pode ser vista, contudo, sob um outro ângulo. Isto é, frente às queixas recorrentes e permanentes, e às vezes exacerbadas dos docentes em relação aos seus alunos, e à falta de condições adequadas para seu trabalho, pode-se pensar que, no fundo, muitos dos professores são refratários à reflexão e à necessidade de se questionarem sobre suas prática e investimento no trabalho. Com isso, é mais fácil colocar a culpa nos alunos, nas condições de trabalho não satisfatórias, do que questionar o seu próprio trabalho.

Nas escolas observadas, por exemplo, ficamos sabendo que vários professores pediram para mudar de nível de ensino no ano em que o novo programa começou a ser implantado, isto é, pediam para passar das primeiras séries do primeiro ciclo para as séries terminais do segundo ciclo do secundário, acreditando que com isso retardariam a entrada no novo programa ou, como foi o caso de alguns que estavam em vias de se aposentar, se livrariam completamente de fazê-lo. Vale ressaltar, entretanto, que diferentemente desses casos que mencionamos, entre os nossos depoentes estão duas professoras de matemática exemplares e extremamente engajadas na reforma, uma das quais se aposentaria naquele ano enquanto a outra estava em vias de fazê-lo, e que nem por isso fugiram ao desafio que impunha a colaboração no quadro da implantação do novo programa. 


\section{Conclusão}

Este estudo não esgota a discussão sobre a problemática da colaboração. Ele permite modestamente verificar e pôr à prova certas constatações decorrentes de outras pesquisas sobre o tema e, igualmente, lançar alguns questionamentos sobre os ideais subjacentes à onda colaborativa proclamada nas reformas e nas políticas atuais.

Pode a colaboração vir a ser uma nova forma de solidariedade no trabalho? O que se ganha com ela? O que seria arriscado perder na organização escolar se a colaboração passar a ser uma norma? Pode a colaboração constituir um desafio, um problema à identidade dos docentes do secundário? Trata-se de problema relativo às concepções que os docentes nutrem das suas próprias matérias de ensino? Ou é sobretudo uma questão de concepção de escola, de ensino, de poder e de participação nas decisões locais a serem tomadas em relação ao "trabalho curricular" (TARDIF; LESSARD, 1999), isto é, trabalho de transformação e de adaptação dos conhecimentos inscritos no programa em conhecimentos ensináveis nas salas de aula? Mas, em se tratando de um problema identitário, sobre quais aspectos devemos nos debruçar a fim de passar de uma relação de "independência", na qual os professores colaboram pouco e partilham pouco o seu trabalho, à uma relação de "interdependência" em que eles colaborariam e partilhariam com mais freqüência as tarefas de planificação, de elaboração, de avaliação, de ensino etc.? (LIT'TLE, 1990)

Mas pode a colaboração vir a ser um ideal profissional a ser perseguido e uma fonte de transformação profunda das práticas e da cultura escolar docente? $\mathrm{O}$ estudo que mencionamos no início deste artigo, tratando de dois programas de desenvolvimento profissional (LITTLE, 1984), bem como nossas análises indicam que a colaboração é viável. Porém, sob certas condições: implicação efetiva dos docentes nas decisões que afetam o programa, mas também, naquelas que dizem respeito à divisão de tarefas, à grade de horários, aos tempos e espaços de trabalho; liderança dos diretores etc.

Nós podemos nos questionar, enfim, se a colaboração não seria, com toda evidência, uma norma a serviço de uma nova regulação no trabalho. Visto que os professores resistem aos processos avaliativos internos e entre pares, e considerando que eles vivem pressionados pelos exames ministeriais, pelos pais de alunos, pela competição entre as escolas 
etc., a colaboração por tudo o que ela implica em termos de confrontação de idéias e de práticas seria vista como uma nova forma de regulação interna das praticas escolares e dos gestos profissionais dos docentes. Nesse caso, a quem serviria a colaboração? Aos diretores de escola, aos políticos, ao quadro professoral?

O tempo nos dirá se a colaboração preconizada pelas orientações reformista será ou não integrada às praticas docentes, passando de um "modismo" a um elemento essencial na base da organização escolar.

\section{REFERÊNCIAS}

BARRÈRE, A. Les enseignants au travail. Routines incertaines. Paris: l'Harmattan, 2002a.

Pourquoi les enseignants ne travaillent-ils pas en équipe? Sociologie $d u$ travail, Elsevier, n. 44, p. 481-497, 2002b.

BORGES, C. O professor da educação básica e seus saberes profissionais. Araraquara: JM Editores, 2004.

BORGES, C.; LESSARD, C. Enseigner autrement à l'école secondaire? L'annuaire du Québec 2005. Québec: Éditions FIDES, 2005. p. 329-334.

Qu'arrive-t-il quand la collaboration enseignante devient une norme? In: MARCEL, J-F.; DUPRIEZ, V.; PÉRISSET-BAGNOUD, D; TARDIF, M. (Ed.). Coordoner, collaborer, coopérer, des nouvelles pratiques enseignantes. France/Belgique: DeBoeck, 2006. (No prelo).

CONSEIL SUPÉRIEUR DE L'ÉDUCATION (CSÉ). L'appropriation local de la réforme: un défi à la mesure de l'école secondaire. Québec, Qc: CSÉ. 2003.

DARLING-HAMMOND, L.; CHUNG, R; FRELOW, F. How well do different pathways prepare teachers to teach. Journal of Teacher Education, University of Colorado, AACTE, v. 53, n. 4, p. 286-302, Sept./Oct. 2002.

DUPRIEZ, V. Les représentations et les pratiques éducatives comme fondement de la coordination du travail dans les écoles? In: MARCEL, J-F. et al. (Ed.). Coordoner, collaborer, coopérer, des nouvelles pratiques enseignantes. France/Belgique: DeBoeck, 2006. (No prelo).

GROSSMAN, P. L.; STODOLSKY, S. S. Content as Context: The Role of Subjects Secondary School Teaching. Education Researcher, Washington, DC, AERA, v. 24, n. 8, p. 5-11, Nov. 1995.

INGER, M. Teacher collaboration in Secondary Schools. Center Focus, [on-line] Center Focus Archive. Berkeley, University of California, n. 2, Dec. 1993. Disponível em: <//http://vocserve.berkeley.edu/CenterFocus/CF2.html>. 
LANDT, S. M. Cooperating teachers and professionnal developpement. The Educational Resources Information Center (ERIC), United States of America, Departement of education, 2002. 36 p.

LEONARD, L.; LEONARD, P. The continuing trouble whith colaboration teachers talk. Current Issus in Education. Arizona State University, v. 6, n. 15, 2003. Disponível em: <http:/cie.ed.asu/volume6/number15>.

LESSARD, C. La collaboration au travail: des finalités à débattre entre la formulation d'une norme professionnelle et le développement d'une pratique. In: BIRON, D.; CIVIDINI, M.; DESBIENS, J-F. La profession enseignante aux temps de réformes. Sherbrooke: Éditions du CRP, 2005. p. 435-458.

LESSARD, C.; MEIRIEU, P. (Dir.). L'obligation de résultats en éducation. Québec: PUL et Paris : De Boeck, 2004.

LESSARD, C.; TARDIF, M. Les identités enseignantes. Sherbrooke: Éditions du CRP, 2003.

LITTLE, J. W. Seductive Images and Organizational Realities in Professional Developpement. Teachers College Record, New York, Columbia University, v. 86, n. 1, p. 84-102, 1984.

. The persistence of privacy: autonomy and initiative in teachers' professional relations. Teachers College Record, New York: Columbia University, v. 91, n. 4, p. 509-536, 1990.

LITTLE, J. W. Inside Teacher Community: Representations of Classroom Practice. Teachers College Record, New York: Columbia University, v. 105, n. 6, p. 913-945, 2003.

LORTIE, D. C. Schoolteacher: a sociological study. Chicago: University of Chicago Press, 1975.

MINISTÈRE DE L'ÉDUCATION DU QUÉBEC. Programme de formation de l'école québécoise. Enseignement secondaire. Québec, Canada, 2003.

Programme de formation de l'école québécoise. Enseignement préscolaire primaire. Québec, Canada, 2001.

Loi sur l'Instruction Publique. Québec, Canada. Le 7 mars 2003.

MINISTÈRE DE L'ÉDUCATION DU LOISIR ET DU SPORT. Information et reddition de comptes des établissements scolaires aux parents et à la communauté. Québec, Canada, 2004.

ONTARIO COLLEGE TEACHERS. Standards of practice for the Teaching profession. Gouvernment of Ontario, Canada, 1999.

OSBORN, M., MCNESS, E.; BROADFOOT, P. What teachers do: changing policys and practices in a primary education. Classell/London: Continuum, 2002. 
PÉRISSET-BAGNOUD, D. De la solitude de l'enseignant à la re-découverte des cycles d'apprentissage. Une histoire de professionnalité autonome et responsable, In: MARCEL, J-F. et al. (Ed.). Coordoner, collaborer, coopérer, des nowvelles pratiques enseignantes. France/Belgique: DeBoeck, 2006. (No prelo).

ROSENHOLTZ, S. J. Teachers' workplace: the social organization of schools. White Plains, NY: Logman, 1991.

SISKIN, L. S. Departements as differents worlds: subjects subcultures in secondary schools. Educational Administration Quaterly, Salt Lake City: University of Utah, v. 27, n. 2, p. 134-160, May 1995.

STODOLSKY, S. S. A framework for subjet matter comparaisons in high school. Teacbing and Teacher Education, n. 9, p. 333-346, 1993.

STODOLSKY, S. S.; GROSSMAN, P. L. The Impact of subject matter on curricular activity: an analyses of five academic subjects. American Educational Research Journal, Washignton, DC: AERA, v. 32, n. 2, p. 227-250, 1995.

TARDIF, M.; LESSARD, C. Le travail enseignant au quotidien. Québec/Bruxelles: Presse de Université Laval/De Boeck, 1999. déc. 2000.

L'école change, la classe reste. Sciences Humaines, Paris, n. 111, p. 22-28,

TARDIF, M; LESSARD, C. (Dir.), La profession d'enseignant aujourd'hui: Évolutions, perspectives et enjeux internationaux. St Nicolas (Québec): Les presses de l'Université Laval, 2004.

TARDIF, M.; LESSARD, C.; GAUTHIER, C. Formation de maître et contextes socianx. Paris: PUF, 1998.

VAN WESSUM, L. Collaboration and teachers perception of professionality in schools of secondary education. In: ANNUAL MEETING OF THE AMERICAN EDUCATION RESEARCH ASSOCIATION. Paper. Montreal, Qc, Canadá: [s.n.], Apr. 1999. p. 19-23.

Recebido em: 30/09/2006

Aprovado em: 06/11/2006 